\title{
Phosphorus and nitrogen co-doped carbon derived from Cigarette Filter for adsorption of methylene blue dye from aqueous solution
}

\section{Samantha Macchi}

University of Arkansas at Little Rock https://orcid.org/0000-0002-7546-4200

\section{Zane Alsebai}

Little Rock Central High School

\section{Fumiya Watanabe}

University of Arkansas at Little Rock

Arooba llyas

University of Arkansas at Little Rock

Shiraz Atif

University of Arkansas at Little Rock

Tito Viswanathan

University of Arkansas at Little Rock

Noureen Siraj ( $\nabla$ nxsiraj@ualr.edu )

University of Arkansas at Little Rock https://orcid.org/0000-0003-4925-0265

\section{Research}

Keywords: doped carbon, adsorption, green chemistry, microwave, cigarette

Posted Date: May 14th, 2021

DOI: https://doi.org/10.21203/rs.3.rs-507326/v1

License: (c) (1) This work is licensed under a Creative Commons Attribution 4.0 International License.

Read Full License 
2 Cigarette Filter for adsorption of methylene blue dye from

4 Samantha Macchi ${ }^{1}$, Zane Alsebai ${ }^{2}$, Fumiya Watanabe $^{3}$, Arooba Ilyas ${ }^{1}$, Shiraz Atif ${ }^{1}$,

$6{ }^{1}$ Department of Chemistry, University of Arkansas at Little Rock, 2801 S. University

$8 \quad{ }^{2}$ Little Rock Central High School, 1500 Park Street, Little Rock, AR 72202, USA

$9 \quad{ }^{3}$ Center for Integrative Nanotechnology Sciences, University of Arkansas at Little 


\section{Abstract}

14 Global access to sanitary water is of utmost importance to human health. Presently,

15 textile dye water pollution and cigarette pollution are both plaguing the environment.

16 Herein, waste cigarette filters are converted into useful carbon-based adsorbent

17 materials via a facile, microwave-assisted carbonization procedure. The cigarette filters

18 are co-doped with phosphorus and nitrogen using ammonium polyphosphate to

19 enhance their surface characteristics and adsorbent capability. The adsorbents are

20 characterized physically to examine their surface area, elemental composition, and

21 surface charge properties. Batch adsorption experiments were performed to determine

22 the maximum adsorption capacity of the adsorbents. Additionally, the effects of various

23 adsorption parameters — temperature, adsorbent dosage, $\mathrm{pH}$, and time — on adsorption

24 process were examined. The doped adsorbent showed a maximum adsorption capacity

25 of $303.3 \mathrm{mg} \mathrm{g}^{-1}$ respectively, which is three times that of the methylene blue adsorption

26 capacity of commercially available activated carbon $\left(\sim 100 \mathrm{mg} \mathrm{g}^{-1}\right)$. Thus, the

27 phosphorus and nitrogen co-doped carbonized waste cigarette filter adsorbent shows a

28 profound potential as a sustainable solution to combat textile dye water pollution and

29 cigarette filter pollution simultaneously, due to its low cost, simple preparation, and 
versatility in application.

31 Keywords: doped carbon; adsorption; green chemistry, microwave, cigarette

\section{Introduction}

33

The textile industry contributes to a considerable amount of water pollution

34 worldwide. According to the National Resources Defense Council, textile mills

35 generate approximately $20 \%$ of industrial water pollution, during which an approximate

3620,000 different chemicals contaminate water [1]. It is estimated that 500,000 textile

37 dyes are produced yearly; these synthetic dyes are immensely stable to light,

38 temperature, and chemical treatment. Moreover these synthetic dyes are resistant to

39 biodegradation under aerobic conditions, and exhibit a high level of solubility in

40 aqueous solutions with visibility to the naked eye at concentrations as low as $1 \mathrm{ppm}$ [2].

41 Due to these characteristics, current large-scale effluent treatments are ineffective for dye removal and high in cost, resulting in an estimated $20 \%$ of dyes being released into the environment.

Several prominent chemical and physical methods are used currently for textile dye removal from effluents, such as coagulation-flocculation, aerobic degradation, and 
relatively simple and inexpensive method [4,5]. Adsorbents researched for dye removal

48 include commercially-available and waste-generated activated carbon utilizing

49 precursors such as tea [6], chitosan [7], and citrus peels [8]. There are also an

50 increasing number of reports using heteroatoms such as nitrogen [9-11], phosphorus

51 [12], or sulfur [13] - doped activated carbon materials, to achieve enhanced

52 adsorption. Many materials have shown promising results using dual or co-doping with

53 two different elements $[14,15]$. In this work, CF waste will be explored as a carbon

54 precursor for synthesis of co-doped carbon material.

55 Cigarette waste contributes to the largest amount of plastic pollution around the

56 world [16]. Most cigarette filters (CFs), the part of the cigarette that remains after

57 smoking, are tossed onto the ground, leading to an immense ecological pollution. CFs

58 are composed mainly of plastic, viz. cellulose acetate, which is not readily

59 biodegradable [17]. Additionally, CFs contain toxic metals that can be leeched into soil

60 and water, causing direct harm to plants and animals [18]. Due to the posed ecological

61 threat of the litter, new methods of reducing cigarette pollution are needed. Since CFs

62 are comprised mostly of cellulose acetate, a carbon-based polymer, these waste

63 products can easily be utilized as carbon precursors for production of activated carbons 

and facile microwave-assisted approach. The phosphorus and nitrogen heteroatom doped carbon contains functional groups which may have a synergistic effect on the adsorption capacity. Both undoped and doped carbons from CF are characterized in

69 detail. Methylene blue (MB) dye is used to investigate the adsorption characteristics of

70 the newly developed phosphorus and nitrogen co-doped carbon from cigarette filter

71 (DCCF) and undoped carbonized cigarette filter (CCF). To the best of our knowledge,

72 no work has reported the use of this one-step microwave-assisted method for producing

73 DCCF and its use as an adsorbent.

\section{Materials and methods}

\subsection{Chemicals} and washed with deionized water to remove any dirt residue, and then they were dried in air prior to their use. The paper casing was removed prior to carbonization.

79 Ammonium polyphosphate (APP, avg mw: 97) was a donation from JLS Chemicals.

80 ACS reagent grade sodium nitrate $\left(\mathrm{NaNO}_{3}\right)$ was purchased from ACROS. Methylene 
81 blue (MB) dye was purchased from Sigma Aldrich. Triply deionized water (18.2 M $\Omega$

$82 \mathrm{~cm}$ ) was obtained using Elga model PURELAB ultra water-filtration system. Reagent

83 grade hydrochloric acid $(\mathrm{HCl})$ and sodium hydroxide $(\mathrm{NaOH})$ were purchased from

84 VWR and dilute $0.01 \mathrm{M}$ solutions were used to adjust $\mathrm{pH}$.

85 2.2. Adsorbent synthesis

86 Waste CFs were collected from receptacles located around UA Little Rock campus

87 and carbonized through a facile, low-cost, microwave-assisted method described

88 previously [22]. For DCCF synthesis, the CFs were weighed and combined with APP

89 in a mass ratio of 1:0.4 g, and 2 drops of water was added to help initiate microwave

90 carbonization process. An undoped carbonized sample of used CF (CCF) was prepared

91 without APP. In this regard, CF with 2 drops of water were placed into a boron nitride

92 crucible, which was promptly situated in a foamed aluminum oxide box to contain the

93 reaction. The box was microwaved for $30 \mathrm{~min}$ at high power $(2.45 \mathrm{GHz}$ and $1.25 \mathrm{~kW}$

94 power) to carbonize the waste filters and then cooled to room temperature after which

95 the resulting products were powdered using a mortar and pestle. This powder was

96 placed in a container and stored in a desiccator for later use. 

techniques. A JSM-7000F scanning electron microscope (SEM) was utilized to

100 determine the morphology and percent elemental composition of the bulk materials.

101 For SEM imaging, a small amount of sample was placed on a double-sided carbon tape

102 on aluminum mount substrate before analysis. ASAP 2020 Micrometrics surface area

103 and porosity analyzer with Brunauer-Emmett-Teller (BET) method was used to

104 analyze surface area and pore size of materials via nitrogen adsorption/desorption

105 studies at a bath temperature of $77 \mathrm{~K}$. Thermo K-Alpha X-ray photoelectron

106 spectrometer (XPS) system was used to determine surface elemental composition of

107 dried carbonized samples. Fourier transform infrared (FTIR) spectroscopy was

108 performed using a Thermo Scientific Nicolet 6700 Spectrometer to confirm that MB

109 was adsorbed onto adsorbent surface and not degraded during adsorption. To determine

110 point of zero charge (PZC), a simple salt addition method was used. Briefly, a

111 suspension of adsorbent $(0.01 \mathrm{~g})$ was prepared in $0.1 \mathrm{M} \mathrm{NaNO}_{3}$ aqueous solution in

112 different reaction vessels $\left(5 \mathrm{~g} \mathrm{~L}^{-1} \mathrm{CCF}\right.$ or DCCF).

113 2.4. Adsorption studies

$114 \quad$ 2.4.1. Adsorbent dosage 
115 To optimize the adsorbent dosage for adsorption, various masses (5-20 mg) were

116 contacted with $50 \mathrm{~mL}$ of $10 \mathrm{ppm} \mathrm{MB}$ solution. After reaching equilibrium $(24 \mathrm{~h})$, the

117 treated MB solutions were centrifuged at 3800 RPM for 10 min to separate the dye

118 solution from the adsorbent. Absorption spectrophotometry (Lambda 850 UV-vis

119 spectrophotometer with $1 \mathrm{~cm}$ path length quartz cuvette) was utilized to determine the

120 concentration of $\mathrm{MB}$ remaining in solution at equilibrium. From this, the percent

121 removal and adsorption capacity were determined.

\subsubsection{Initial concentration}

123 To analyze the effects of MB concentration on the adsorption onto CCF and DCCF

124 from $\mathrm{CFs}$, batch adsorption tests were performed. Using the MB stock solution, $50 \mathrm{~mL}$

$125 \mathrm{MB}$ solutions were prepared with varying concentration (5 ppm to $100 \mathrm{ppm}$ ). $10 \mathrm{mg}$

126 samples of the carbon from the CF and a magnetic stir bar were placed into each of the

127 MB solutions. The solutions were stirred at room temperature at constant speed until

128 they reached equilibrium. The equilibrium data was then fitted into Langmuir and

129 Freundlich isotherm models to determine how the MB interacts with CCF and DCCF.

\subsubsection{Adsorption kinetics}

131 To understand how the uptake of MB by CCF and DCCF is affected by time, 
132 adsorption kinetic tests were performed. Samples containing $50 \mathrm{~mL}$ of various initial

133 concentration of MB solution (5-100 ppm) were prepared and contacted with $10 \mathrm{mg}$ of

134 adsorbent powder and stirred using a magnetic stir bar after which a timer was

135 immediately started. After specified time intervals, an aliquot of the MB solution was

136 analyzed by absorbance spectroscopy. This data was fit into pseudo-first and second

137 order equation to determine the primary mechanism of adsorption for the two materials.

\section{2.4.4. Effect of temperature}

139 Solutions of MB were prepared at $30 \mathrm{ppm}$ and adjusted to various temperatures: 25,

14035,45 , and $55^{\circ} \mathrm{C}$. Then, $10 \mathrm{mg}$ of adsorbent was added and stirred for $24 \mathrm{~h}$. Afterwards,

141 remaining concentration of MB dye was analyzed via absorbance spectrophotometry

142 and adsorption capacity was calculated.

143 2.4.5. Effect of $\mathrm{pH}$

144 Test solutions were prepared using dilute concentrations of $\mathrm{HCl}$ and $\mathrm{NaOH} .10 \mathrm{mg}$

145 of adsorbent was contacted with $50 \mathrm{~mL}$ of $30 \mathrm{ppm}$ initial concentration of MB solution

146 in the flask. The mixture containing constant amount of adsorbent and constant

147 concentration of MB dye was stirred at $120 \mathrm{rpm}$ until equilibrium was achieved (24 h)

148 at various initial $\mathrm{pH}$. 


\section{Results and discussion}

150

\subsection{Physical characterization}

151 3.1.1. SEM

152

Surface morphology of carbonized waste cigarette filters was determined by SEM

153 imaging. SEM image of CCF exhibits a rigid amorphous structure with smaller

154 microstructures decorated on the surface (Figure 1a). Images of DCCF sample display

155 cave-like structures and ridges at the macrostructure with spherical microscale

156 structures distributed throughout (Figure 1b). The doped sample also exhibit more

157 sponge-like morphology indicating that it possesses a more well-developed pore

158 structure than the undoped adsorbent. In order to confirm this, surface area analysis by

159 BET was also performed.

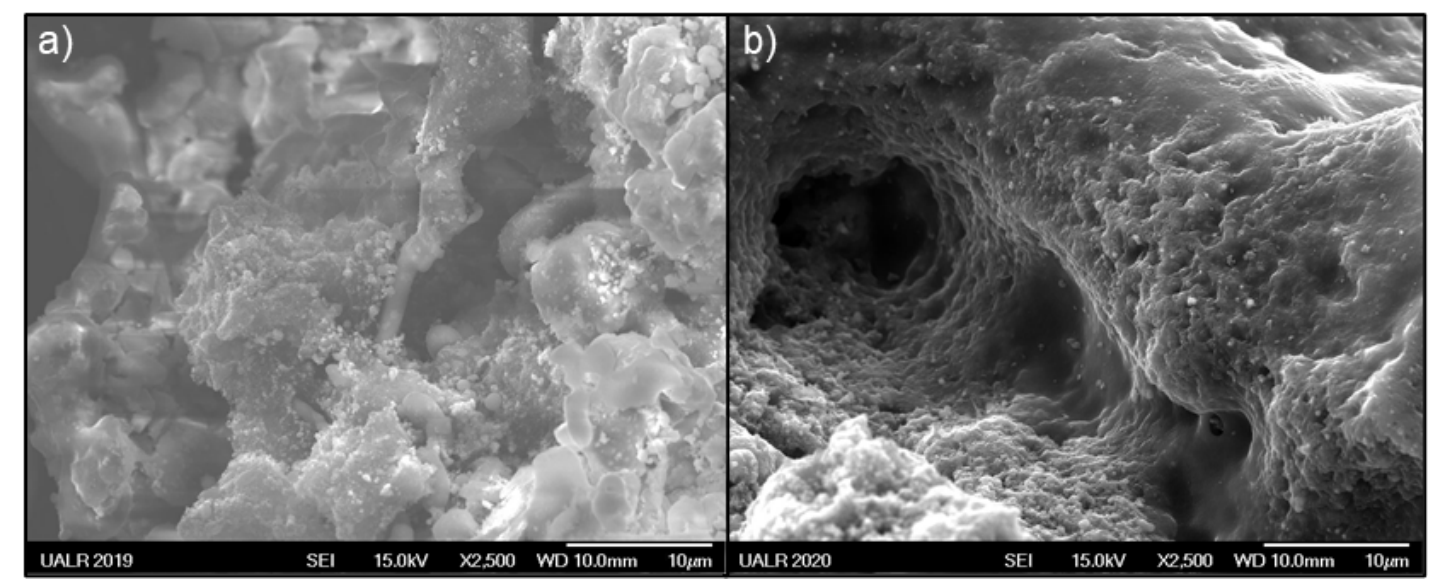

161 Figure 1. SEM images of a) CCF and b) DCCF adsorbents at 2,500 X magnification.

162 3.1.2. BET surface area analysis 
163 Both adsorbents were characterized by BET in order to gain insight into their

164 surface area and porosity. From adsorption-desorption isotherms, both adsorbents

165 exhibit a type IV isotherm characterized by Langmuir-like behavior at relative low

166 pressure and hysteresis loop at higher pressure (Figure 2) [23]. The hysteresis loop is

167 formed by capillary condensation in the mesoporous structures of the material. The

168 BET surface area of CCF and DCCF adsorbents are 176.5 and $177.6 \mathrm{~m}^{2} \mathrm{~g}^{-1}$, respectively.

169 The microwave activation process causes the formation of reducing gases leading to

170 high surface area carbon materials. This result indicates that doping with APP does not

171 play a significant role in enhancing the overall surface area of the activated material.

172 However, DCCF is significantly more mesoporous ( $87.6 \%$ mesopores by volume). This

173 could be due to larger reducing gas formation when combined with APP. The overall

174 results of BET analysis are tabulated in Table 1. 

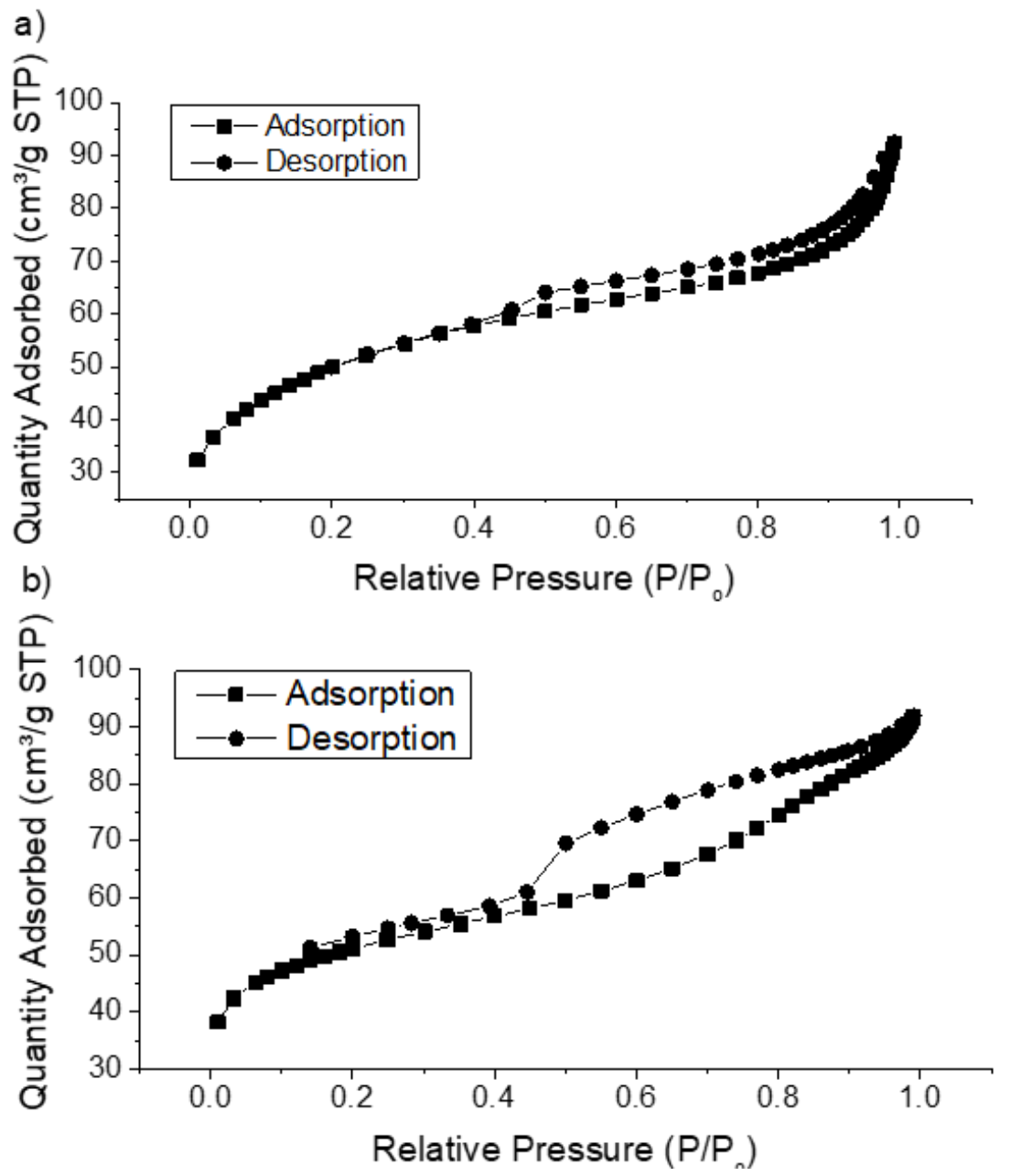

176 Figure 2. Adsorption and desorption curves of a) CCF and b) DCCF.

177 [Table 1]

178 3.1.3. XPS

179 In order to determine surface elemental composition of adsorbent materials, XPS

180 was performed. Various functional groups of atoms at the surface can greatly enhance

181 adsorption mechanism by allowing chemisorption processes to occur. Survey scan

182 spectra of both samples reveal the presence of carbon, oxygen, and phosphorus at the

183 surface (Figure 3). Results of CCF reveals the additional presence of silicon at a low 
184 percentage $(1.13 \%$, Table 2$)$. This is expected, as silicates can be formed in cigarette 185 smoke and deposited in the filter during smoking [24]. DCCF contains much greater 186 amount of phosphorus (3.98\%) and nitrogen at the surface, confirming that the doping 187 of the material was successful. These elements at the surface of adsorbent can aid in 188 binding $\mathrm{MB}$.
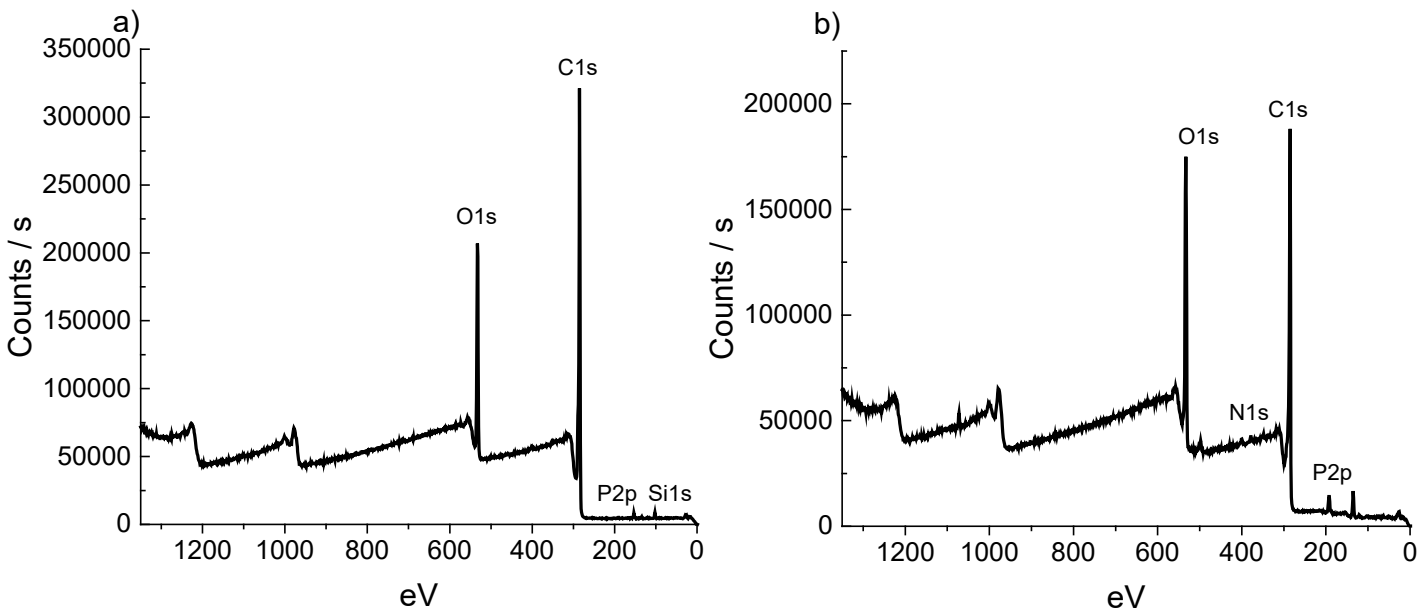

190 Figure 3. Survey scan plots of a) CCF and b) DCCF adsorbents

$191 \quad$ Table 2]

192 3.1.4. PZC

193 The PZC of the adsorbents is analyzed in order to better understand the possible

194 adsorption mechanism onto the materials. The PZC can be defined as the $\mathrm{pH}$ where the net charge of an adsorbent is zero. Since MB is a cationic dye, adsorption is favored when the solution $\mathrm{pH}$ is greater than the PZC of an adsorbent (adsorbent carries net 
201 the doped adsorbent (DCCF) at natural $\mathrm{pH}$.
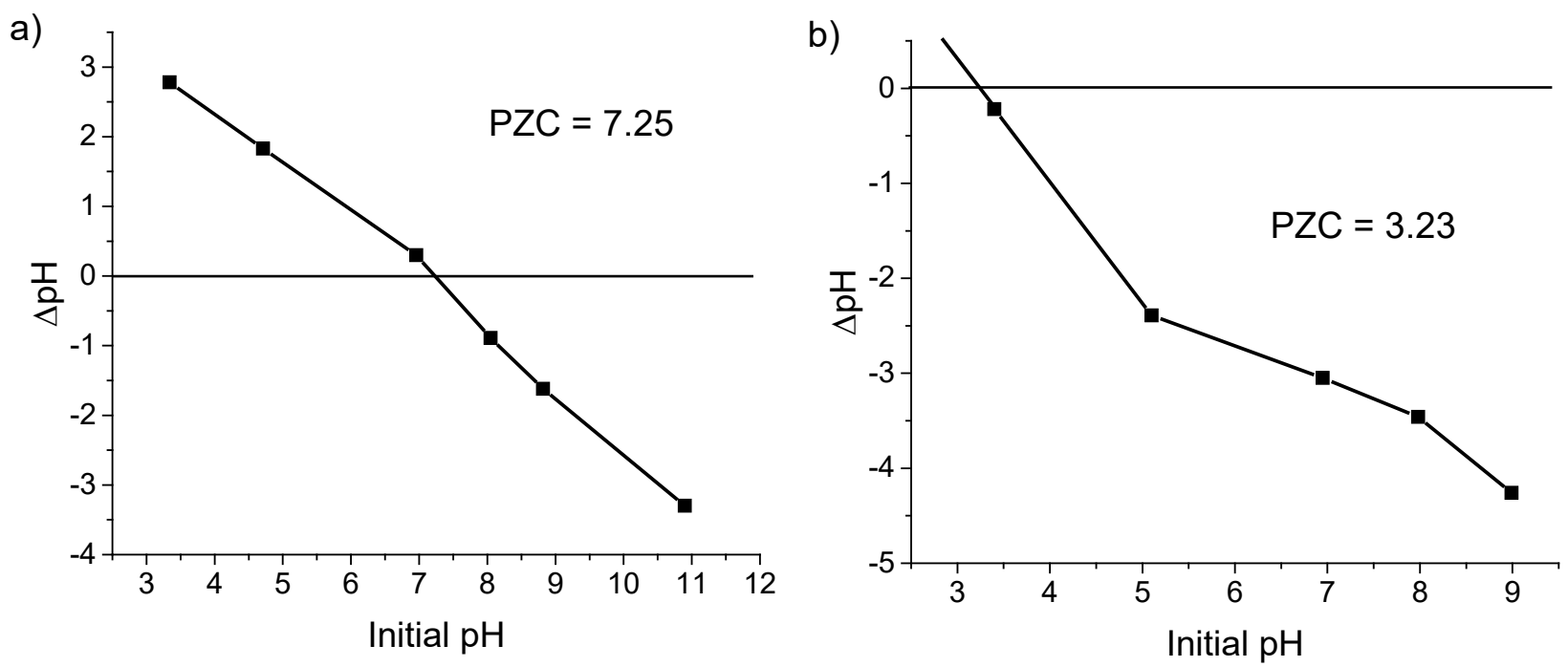

203 Figure 4. Point of Zero Charge $\left(\mathrm{pH}_{\mathrm{zc}}\right)$ plots for a) CCF and DCCF.

207 the raw adsorbent material, there are two additional peaks at 1191 and $1321 \mathrm{~cm}^{-1}$ which

208 are correlated to the $\mathrm{C}=\mathrm{S}$ double bond and the $\mathrm{C}-\mathrm{S}$ bond, respectively. The 
$211 \mathrm{~cm}^{-1}$ was observed for CCF post MB adsorption (Figure S1), indicating a similar

212 nondegradative adsorption process for the undoped sample as well.

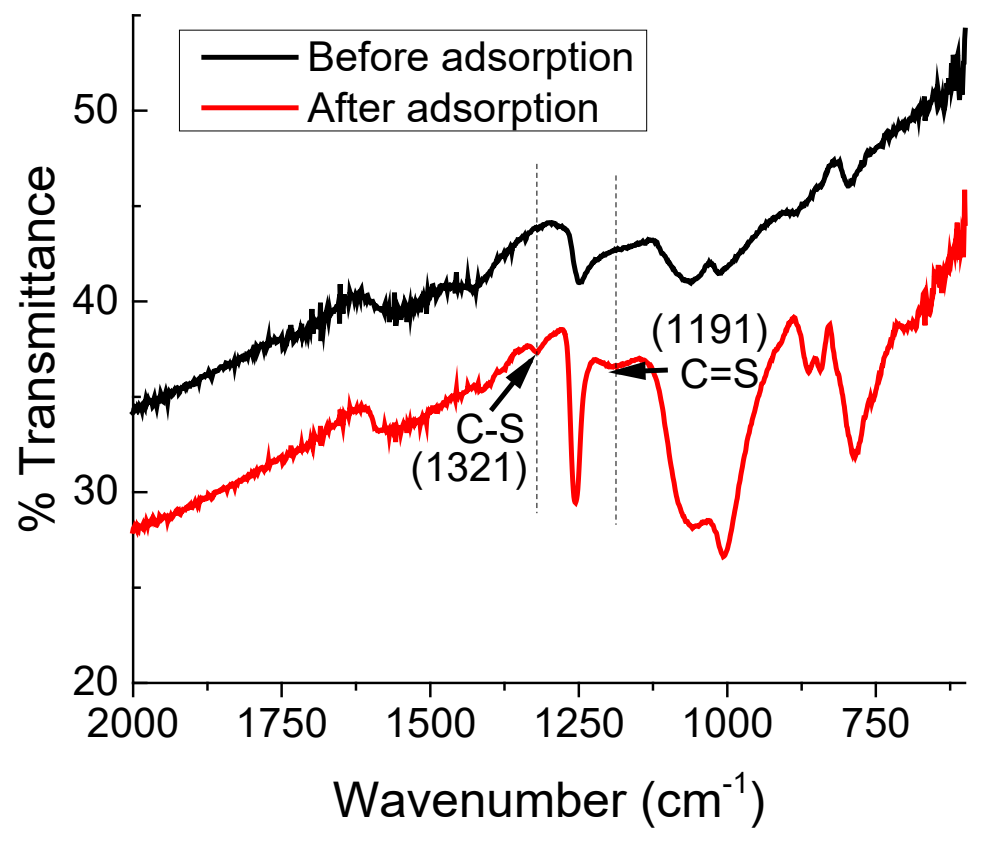

214 Figure 5. FTIR of DCCF adsorbent before and after adsorption of MB

\subsection{Adsorption characterization}

3.2.1. Adsorbent dosage:

$$
\text { Percent Removal }=\left(\frac{C_{0}-C_{e}}{C_{0}}\right) * 100
$$


221 Where $\mathrm{C}$ is the concentration of MB in solution initially and at equilibrium. The amount

222 of dye adsorbed at equilibrium, $\mathrm{Q}_{\mathrm{e}}\left(\mathrm{mg} \mathrm{g}^{-1}\right)$ was calculated by using the following

223 Equation 2:

$224 \quad Q_{e}=\frac{\left(C_{o}-C_{e}\right) V}{W}$

225 Where $\mathrm{V}$ is the volume of solution and $\mathrm{W}$ is the weight of adsorbent. For both

226 samples, percent removal of dye increases with an increase in adsorbent dosage (Figure

227 6). However, $Q_{e}$ increases to a maximum value and then decreases after a certain mass

228 dosage. For CCF, the maximum $\mathrm{Q}_{\mathrm{e}}$ value is obtained at a mass dosage of $10 \mathrm{mg}$. For

229 DCCF, this occurs at a slightly lower mass of $7.5 \mathrm{mg}$. To keep conditions the same for

230 both adsorbents, a mass loading of $10 \mathrm{mg}$ is used for further adsorption experiments.
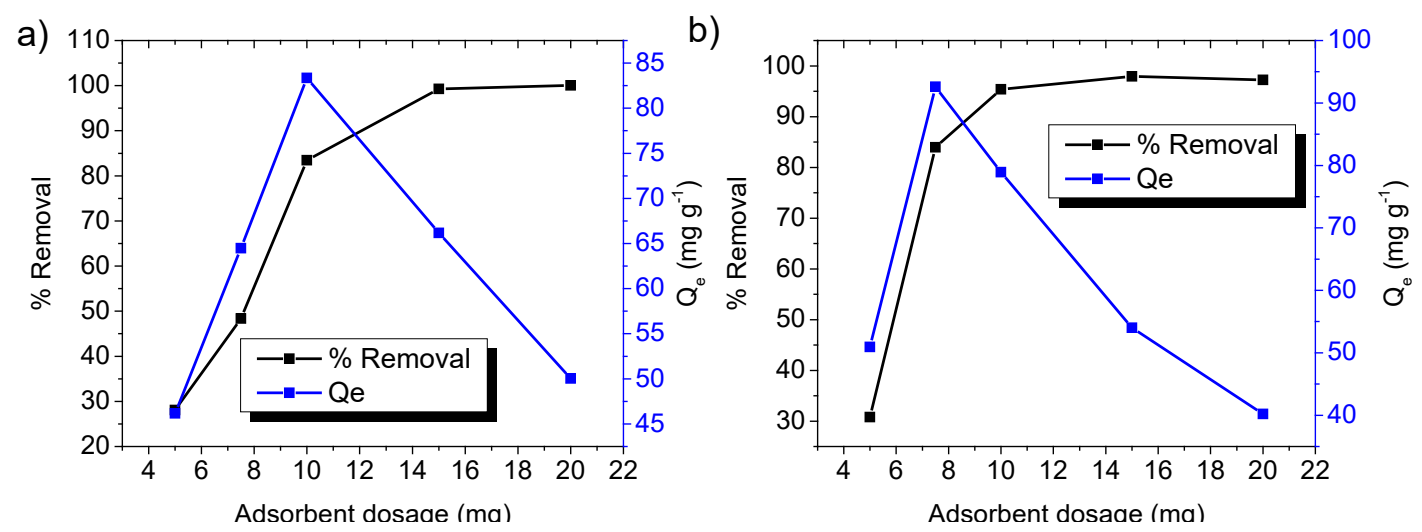

232 Figure 6. Effects of adsorbent dosage on adsorption capacities and \% MB removal for

233

a) CCF and b) DCCF. 
240 adsorption. More dye molecules in the liquid phase shifts equilibrium toward

241 adsorption onto the solid phase. Also, when the initial concentration is very low (5 ppm),

242 both adsorbents exhibit a similar $Q_{e}$ value. However, for CCF, the maximum $Q_{e}$ value

243 achieved is $194.6 \mathrm{mg} \mathrm{g}^{-1}$ while DCCF reaches a value of $293.45 \mathrm{mg} \mathrm{g}^{-1}$. This indicates

244 the enhanced adsorptive capabilities of DCCF compared to CCF.
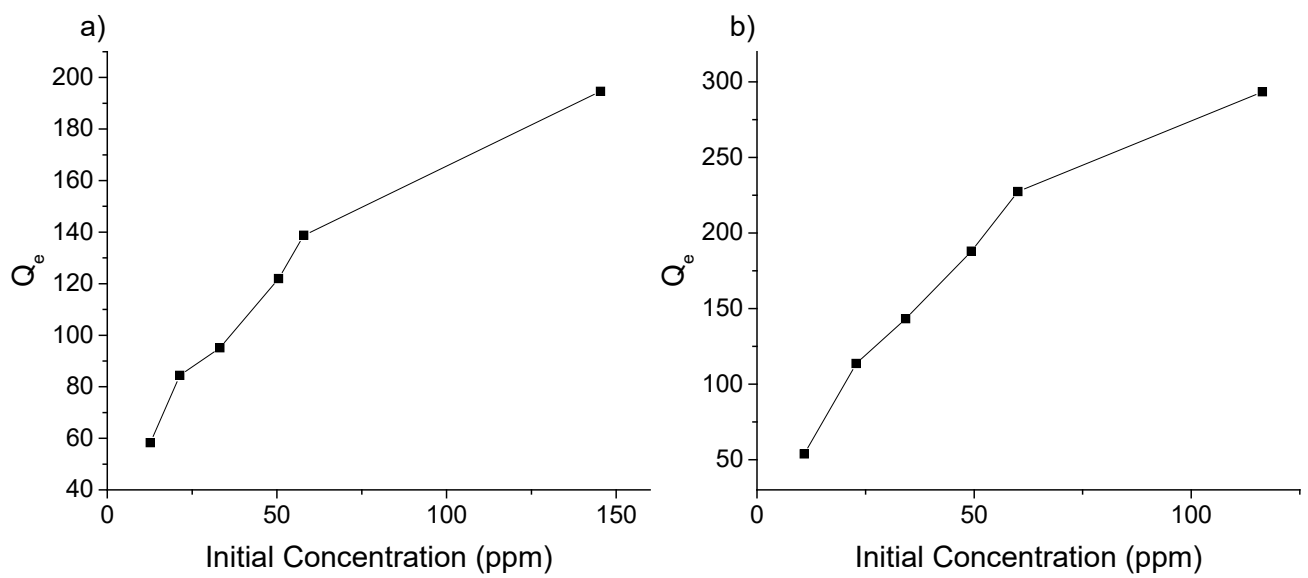

246 Figure 7. Effects of initial MB concentration on the equilibrium adsorption capacity of

247 a) CCF and b) DCCF. 
250 possible adsorption mechanisms. The models help to describe the interactions between

251 adsorbent and dissolved dye species at the liquid-solid phase boundary and allow an

252 estimation of the maximum adsorption capacity. The two most common models,

253 Langmuir and Freundlich models, have been applied to the adsorption data of CCF and

254 DCCF samples.

255 Modelling with the Langmuir equation is performed with several assumptions, one

256 being that only a monolayer of adsorbate can be adsorbed onto the active sites of an

257 adsorbents, and there is a limited amount of these sites. The model also makes the

258 assumptions that those active sites are energetically equivalent regardless of their

259 occupation, meaning the Langmuir equation does not consider repulsive forces of

260 molecules bound to adsorbent surface. The linear form of the Langmuir equation [25]

261 (Equation 3) was used to determine the Langmuir constants related to maximum

262 adsorption amount per unit gram of adsorbent $\left(\mathrm{Q}_{\max }\right)$ and related to the energy of

263 adsorption $\left(\mathrm{K}_{\mathrm{L}}\right)$

$264 \quad \frac{C_{e}}{Q_{e}}=\frac{1}{Q_{\max } K_{L}}+\frac{1}{Q_{\max }} C_{e}$ 

possesses a higher capacity to adsorb MB from solution. The $\mathrm{K}_{\mathrm{L}}$ value of DCCF is also much higher than CCF ( 0.38 vs 0.08$)$ indicating a stronger interaction between doped

269 sample surface and the adsorbate. Both models showed reasonable fitting with $\mathrm{R}^{2}$

270 values of 0.911 and 0.986 for CCF and DCCF, respectively.

271 Modelling with the Freundlich equation is done with the assumptions that the

272 adsorbent surface is heterogeneous and that the adsorption sites are of varying energy.

273 The Freundlich equation (Equation 4) was also used in the linear form:

$274 \quad \log Q_{e}=\log K_{F}+\frac{1}{n} \log C_{e}$

275 Where $\mathrm{K}_{\mathrm{F}}$ and $\mathrm{n}$ are constants related to adsorption capacity and intensity, respectively.

276 Neither adsorbent was well represented by the model with $\mathrm{R}^{2}$ values less than 0.88 in

277 both cases. However, both adsorbents possess an $\mathrm{n}$ value greater than 1 which is 278 indicative of a favorable process of adsorption. The $\mathrm{n}$ value of DCCF is greater than 279 that of CCF (Table 3) which can be correlated to a stronger interaction between 280 adsorbate and adsorption sites on the surface of the adsorbent material. $K_{F}$ values are 
281 related to adsorption capacity and, like Langmuir modelling of the data, DCCF exhibits

282 a higher $K_{F}$ value. Langmuir and Freundlich fitting plots are displayed in Figure S2.

283 To investigate the spontaneity of the adsorption onto the two different adsorbents,

284 Gibbs free energy was calculated from Equation 5.

$285 \Delta G^{o}=-R T \ln k_{0}$

286 where $\mathrm{R}$ is the gas constant $\left(8.314 \mathrm{~J} \mathrm{~mol}^{-1} \mathrm{~K}^{-1}\right)$ and $\mathrm{T}$ is the temperature $(298 \mathrm{~K})$, and

$287 \mathrm{k}_{0}$, is equal to $\mathrm{Q}_{\mathrm{e}} / \mathrm{C}_{\mathrm{e}}[26]$. Both $\mathrm{CCF}$ and DCCF exhibited spontaneous adsorption

288 processes, indicated by negative values of $\Delta \mathrm{G}^{\circ}$. DCCF value of $\Delta \mathrm{G}^{\circ}$ is lower than CCF,

289 indicating increased spontaneity of adsorption process upon conversion to doped

290 carbon material. $\Delta \mathrm{G}^{\mathrm{o}}$ values for both adsorbents are listed in Table 3.

$291 \quad$ [Table 3]

$292 \quad 3.2 .4$. Kinetics

293 In order to gain insight on the kinetic mechanism of adsorbents, kinetic adsorption

294 was fitted into pseudo-first and pseudo-second order kinetic models. Experiments were

295 performed by varying initial concentration from 5 to $100 \mathrm{ppm}$ of $\mathrm{MB}$ at natural $\mathrm{pH}$ and

296 recording the dye concentration at various time intervals after contact with adsorbent 
(Figure $8 \mathrm{a}$ and $8 \mathrm{~b}$ ). The pseudo-first order model was used in the linear form (Equation

$6)$ in order to evaluate the first order rate constant, $\mathrm{k}_{1}$.

299

$$
\log \left(Q_{e}-Q_{t}\right)=\log Q_{e}-\frac{k_{1}}{2.303} t
$$

300 Where $\mathrm{Q}_{\mathrm{t}}$ is the amount of dye adsorbed at time, $\mathrm{t} . \mathrm{R}^{2}$ values were used to determine

301 the better fitting model. The pseudo-second order equation was also used in the linear

302 form (Equation 7) to determine second order rate constant, $\mathrm{k}_{2}$.

$303 \quad \frac{t}{Q_{t}}=\frac{1}{k_{2} Q_{e}^{2}}+\frac{1}{Q_{e}} \mathrm{t}$

304 Plotting the linear form of Equation 6 and 7 generates a straight line in which $\mathrm{k}$ can

305 be directly calculated (Figure $8 c, 8 d, S 2 a$, and S2b). CCF average $\mathrm{R}^{2}$ value is 0.88

306 (Table S1) while the average value of $\mathrm{R}^{2}$ for second order fitting is 0.99 . This indicates

307 a better fitting of CCF adsorption to pseudo-second order kinetics. DCCF average $\mathrm{R}^{2}$

308 value for pseudo-first order plot is 0.90 while for pseudo-second, the value average is

309 0.99. This indicates that the adsorption mechanism is better correlated to a pseudo-

310 second order process for both samples. This process is characterized by strong

311 chemisorptive adsorption between MB and CCF and DCCF adsorbents. In addition, the

312 standard deviation was calculated from Equation 8:

$$
\Delta Q(\%)=100 \times \sqrt{\frac{\sum\left[\frac{Q_{t, e x p}-Q_{t, c a l}{ }^{2}}{Q_{t, e x p}}\right.}{n-1}}
$$


314 For CCF adsorption, $\Delta Q$ was found to be between 1.03-8.48 for second order

315 compared to 6.98-19.90 for first order (Table S1). Similarly, DCCF displayed $\Delta Q$

316 values between 4.52-16.97 for pseudo-first order and 4.89-8.44 for pseudo-second

317 order. This data further supports a chemisorptive mechanism of adsorption for the two

318 adsorbents.

319
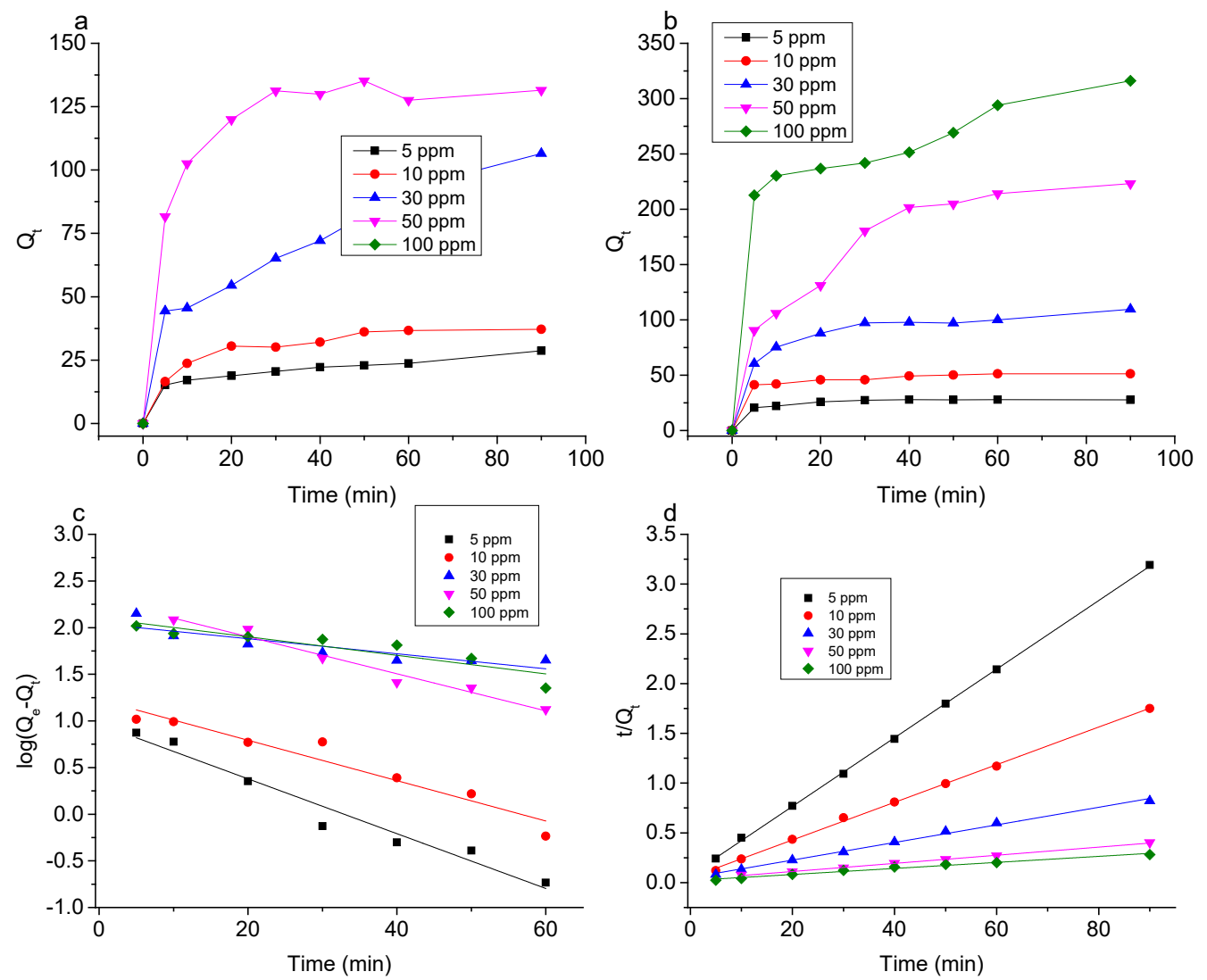

320 Figure 8. Kinetics plot of a) CCF and b) DCCF and pseudo c) first and d) second order

321 fitting of data of doped sample.

The adsorption capacity of CCF and DCCF were compared to those of other waste- 
324 and corresponding maximum adsorption capacities are reported in Table 4. From this

325 data, it can be concluded that CCF and DCCF show exceptional application as

326 adsorbent materials for removal of the cationic MB dye as their adsorption capacities

327 are higher than many other waste-derived carbons. Additionally, many of the

328 previously used waste precursors require chemical activation, whereas this work

329 highlights a simplistic method to produce doped carbons with desirable adsorption

330 characteristics.

331 [Table 4]

332 3.2.5. Effect of temperature:

333 In order to evaluate the temperature effect on adsorption onto the cigarette-based

334 samples, experiments were performed at four different temperatures ranging from 25

335 to $55^{\circ} \mathrm{C}$. It is observed that for both adsorbent materials, the adsorption capacity, $\mathrm{Q}_{\mathrm{e}}$ is

336 increasing as the temperature increases (Figure 9). This is due to an increased diffusion

337 rate of $\mathrm{MB}$ molecules into the internal cavities of porous carbons [25]. This occurs

338 mainly due to the lowering of viscosity of the solvent as temperature increases. This is

339 also indicative of an endothermic adsorption process for both adsorbents [27]. 


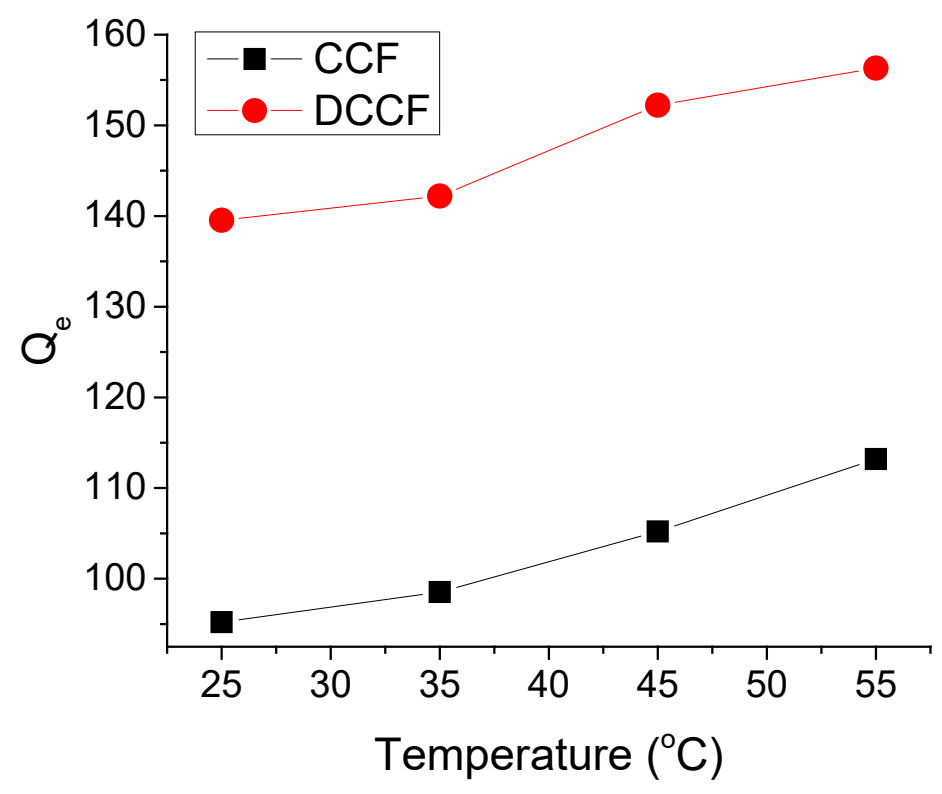

341 Figure 9. Effect of temperature on equilibrium adsorbent capacity from initial

342 concentration of $30 \mathrm{ppm}$ and $10 \mathrm{mg}$ adsorbent dosage.

343 3.2.6. Effect of $\mathrm{pH}$ :

344 The effect of solution $\mathrm{pH}$ on $\mathrm{MB}$ adsorption was determined by contacting $10 \mathrm{mg}$

345 of adsorbent to $50 \mathrm{~mL}$ of $30 \mathrm{ppm} \mathrm{MB}$ solution (Figure 10). CCF adsorption is greatly

346 dependent on $\mathrm{pH}$, ranging from $77.6 \mathrm{mg} / \mathrm{g}$ to $99.7 \mathrm{mg} / \mathrm{g}$ in a $\mathrm{pH}$ range from 3.9 to 10.2 .

347 This is due to the neutral PZC of CCF. Below $\mathrm{pH} 7$, the adsorption is unfavored because

348 of the repulsive forces between MB and the positive adsorbent surface. In contrast,

349 DCCF adsorption capacity remains relatively unchanged over the $\mathrm{pH}$ range 3.35 to

350 10.89. This is because of a low PZC value of DCCF, causing it to have a net negative

351 surface charge at $\mathrm{pH}$ past 3.23 . 

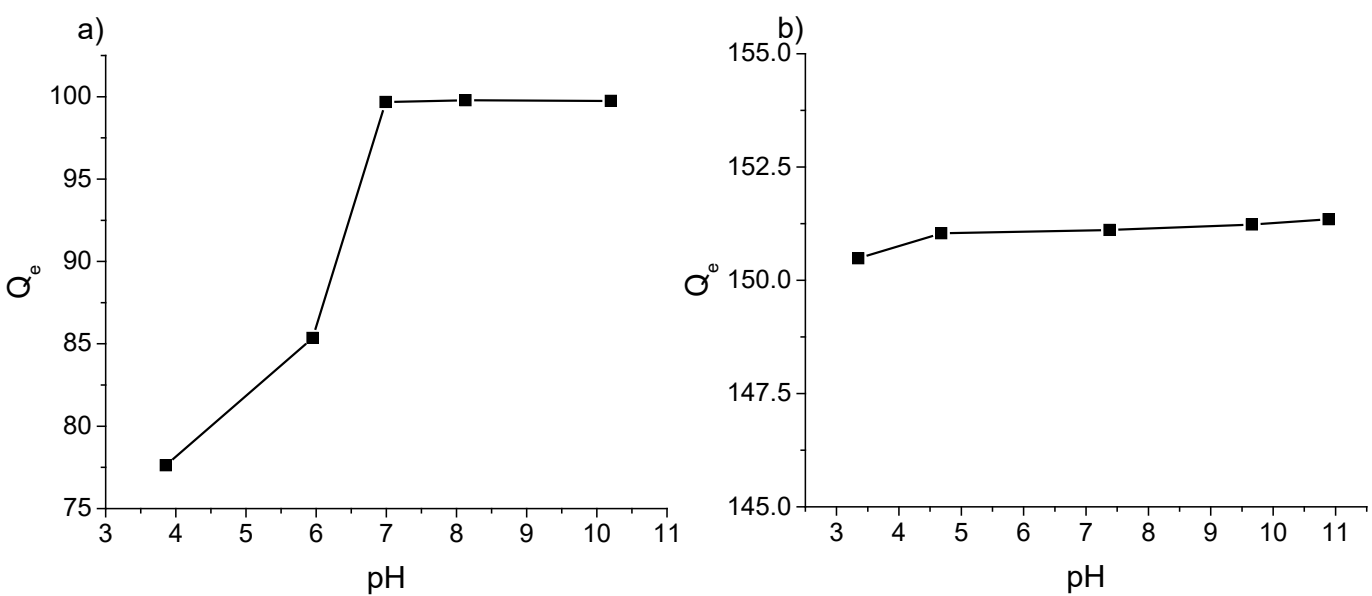

353 Figure 10. Effect of initial solution $\mathrm{pH}$ on adsorption capacity of a) CCF and b) DCCF

354 using an initial $50 \mathrm{~mL}$ of $30 \mathrm{ppm} \mathrm{MB}$ solution.

\section{Conclusions}

rapid one-step microwave synthesis. DCCF exhibited an exceptional maximum adsorption

358 value of $303.0 \mathrm{mg} \mathrm{g}^{-1}$, making it a very efficient and low-cost adsorbent. The materials were

359 characterized in detail to reveal crucial information about their surface area, elemental

360 composition, and morphology. The adsorbents were found to have high surface area $\left(\sim 177 \mathrm{~m}^{2}\right.$

$361 \mathrm{~g}^{-1}$ ) and well-developed porosity. Doping of the sample was confirmed using XPS which

362 showed significant contribution of phosphorus and nitrogen on the surface of the material which

363 played a significant role in enhancing the adsorption capacity of the material. Adsorption of

364 MB onto adsorbents was found to be best correlated to a monolayer adsorption process as 
second order adsorption process which is indicative of a chemisorptive process. Adsorption

onto the adsorbents is spontaneous $(\Delta \mathrm{G}<0)$ and endothermic in nature. This work highlights an

remediation.

\section{$\underline{\text { Declarations }}$}

\section{$371 \quad$ Availability of data and materials}

372 The datasets generated during and/or analyzed during the current study are available

373 from the corresponding author on reasonable request.

\section{Competing interests}

375 The authors declare they have no competing interests.

\section{$376 \quad$ Funding}

377 This research acknowledges the Signature award funding and startup funds from the

378 University of Arkansas at Little Rock

\section{Authors' contributions}

380 S.M., Z.A, A.I., and S.A collected adsorption data and performed data analysis. S.M.

381 and F.W. collected physical characterization data. T.V. and N.S. provided

382 supervision, project administration, and acquisition of funding. Writing and original 
383 draft preparation was conducted by S.M. and N.S. All authors read and approved the

384 final manuscript.

385 Acknowledgements

386 The authors acknowledge Center for Integrative Nanotechnology Sciences for

387 characterization instrumentation.

388 References

389 1. Greer B, Maul R, Campbell K, Elliott CT. Detection of freshwater cyanotoxins

390 and measurement of masked microcystins in tilapia from Southeast Asian

$391 \quad$ aquaculture farms. Anal Bioanal Chem 2017;409:4057-69.

392 2. Lellis B, Fávaro-Polonio CZ, Pamphile JA, Polonio JC. Effects of textile dyes on health and the environment and bioremediation potential of living organisms. Biotechnol Res Innov 2019;3:275-90.

395 3. Mazille F, Spuhler D. Coagulation-Flocculation. 2014.

396 4. Kandisa RV, Saibaba KV N. Dye Removal by Adsorption: A Review. J Bioremediation Biodegrad 2016;07.

398 5. Buhani, Wijayanti TA, Suharso, Sumadi, Ansori M. Application of modified green algae Nannochloropsis sp. as adsorbent in the simultaneous adsorption of 
402 6. Sikdar D, Goswami S, Das P. Activated carbonaceous materials from tea waste and its removal capacity of indigo carmine present in solution: synthesis, batch and optimization study. Sustain Environ Res 2020;30:1-16. derived from chitosan: An excellent cathode catalyst in microbial fuel cell. Chem Eng J 2019;358:1002-11.

8. Nageeb M. Adsorption Technique for the Removal of Organic Pollutants from Water and Wastewater. Org. Pollut. - Monit. Risk Treat., InTech; 2013. orange dye on nitrogen-doped mesoporous carbon materials. J Colloid Interface Sci 2016;466:343-51. doped microporous biochar derived from crop straws with high dye adsorption capacity. J Environ Manage 2016;176:61-8. 
of N-doped porous carbon nanosheets for dye adsorption and supercapacitor applications. Nanoscale 2019;11:8785-97.

419 12. Silva TL, Cazetta AL, Souza PSC, Zhang T, Asefa T, Almeida VC. Mesoporous activated carbon fibers synthesized from denim fabric waste: Efficient adsorbents for removal of textile dye from aqueous solutions. J Clean Prod 2018;171:482-90.

423 13. Vigneshwaran S, Sirajudheen P, Karthikeyan P, Meenakshi S. Fabrication of sulfur-doped biochar derived from tapioca peel waste with superior adsorption performance for the removal of Malachite green and Rhodamine B dyes.

14. Macchi S, Siraj N, Viswanathan T. Kinetic and mechanistic study of dye sorption Surfaces and Interfaces 2021;23:100920.

430 15. Roldán L, Marco Y, García-Bordejé E. Bio-sourced mesoporous carbon doped with heteroatoms $(\mathrm{N}, \mathrm{S})$ synthesised using one-step hydrothermal process for water remediation. Microporous Mesoporous Mater 2016;222:55-62.

433 16. Qamar W, Abdelgalil AA, Aljarboa S, Alhuzani M, Altamimi MA. Cigarette 
17. Puls J, Wilson SA, Hölter D. Degradation of Cellulose Acetate-Based Materials:

18. Moerman JW, Potts GE. Analysis of metals leached from smoked cigarette litter.

19. Xiong Q, Bai Q, Li C, Li D, Miao X, Shen Y, et al. Nitrogen-doped hierarchical Chem Eng 2019;95:315-23.

20. Lee M, Kim GP, Don Song H, Park S, Yi J. Preparation of energy storage material porous carbons from used cigarette filters for supercapacitors. J Taiwan Inst

21. Kim GP, Lee M, Song HD, Bae S, Yi J. Highly efficient supporting material derived from a used cigarette filter for a supercapacitor electrode. Nanotechnology 2014;25:345601. 
23. Sing KSW, Everett DH, Haul RAW, Moscou L, Pierotti RS, Rouquerol J, et al. Reporting physisorption data for gas/solid systems with special reference to the determination of surface area and porosity. Pure Appl Chem 1985;57:603-19.

24. Pappas RS. Toxic elements in tobacco and in cigarette smoke: Inflammation and sensitization. Metallomics 2011;3:1181-98.

25. Nasuha N, Hameed BH, Din ATM. Rejected tea as a potential low-cost adsorbent for the removal of methylene blue. J Hazard Mater 2010;175:126-32.

26. Archin S, Sharifi SH, Asadpour G. Optimization and modeling of simultaneous tobacco residues: Response surface methodology. J Clean Prod 2019;239. Adsorption of congo red and methylene blue dyes on an ashitaba waste and a walnut shell-based activated carbon from aqueous solutions: Experiments, characterization and physical interpretations. Chem Eng J 2020;388:124263. 
29. Reffas A, Bernardet V, David B, Reinert L, Lehocine MB, Dubois M, et al. Carbons prepared from coffee grounds by H3PO4 activation: Characterization and adsorption of methylene blue and Nylosan Red N-2RBL. J Hazard Mater 2010;175:779-88.

30. Rashid RA, Jawad AH, Ishak MABM, Kasim NN. FeCl3-activated carbon blue removal. Sains Malaysiana 2018;47:603-10.

31. Hu W, Xie Y, Lu S, Li P, Xie T, Zhang Y, et al. One-step synthesis of nitrogendoped sludge carbon as a bifunctional material for the adsorption and catalytic oxidation of organic pollutants. Sci Total Environ 2019;680:51-60.

32. Dorothy A, Mideen AS. Adsorption of Methylene blue dye on activated carbon from rice husk. J Chem Pharm Res 2015;7:761-5. sorption of crystal violet and methylene blue from aqueous solutions onto an agro-waste derived activated carbon. Appl Water Sci 2020;10:132. 
485 Table 1. Surface area characteristics from BET.

Sample BET surface area Pore volume Micropore volume Mesopore volume Average pore

\begin{tabular}{cccccc} 
& $\left(\mathrm{m}^{2} \mathrm{~g}^{-1}\right)$ & $\left(\mathrm{cm}^{3} \mathrm{~g}^{-1}\right)$ & $\left(\mathrm{cm}^{3} \mathrm{~g}^{-1}\right)$ & $\left(\mathrm{cm}^{3} \mathrm{~g}^{-1}\right)$ & width $(\AA)$ \\
\hline $\mathrm{CCF}$ & 176.5 & 0.140 & 0.042 & 0.098 & 31.7 \\
$\mathrm{DCCF}$ & 177.6 & 0.137 & 0.017 & 0.120 & 31.1 \\
\hline
\end{tabular}

486 Table 2. Surface elemental composition (At\%) of adsorbents

\begin{tabular}{lcc}
\hline Element & CCF & DCCF \\
\hline C1s & 80.77 & 72.56 \\
O1s & 17.8 & 21.91 \\
P2p & 0.30 & 3.98 \\
N1s & --- & 0.90 \\
Si2p & 1.13 & --- \\
\hline
\end{tabular}

487

488

489

490 
491 Table 3. Langmuir and Freundlich constant value results from linear fitting and free

492 energy values for CCF and DCCF

\begin{tabular}{|c|c|c|c|}
\hline Isotherm & Parameter & $\mathrm{CCF}$ & DCCF \\
\hline \multirow[t]{3}{*}{ Langmuir } & $\mathrm{Q}_{\max }\left(\mathrm{mg} \mathrm{g}^{-1}\right)$ & 212.8 & 303.0 \\
\hline & $\mathrm{K}_{\mathrm{L}}\left(\mathrm{L} \mathrm{mg}^{-1}\right)$ & 0.08 & 0.38 \\
\hline & $\mathrm{R}^{2}$ & 0.911 & 0.986 \\
\hline \multirow[t]{3}{*}{ Freundlich } & $\mathrm{K}_{\mathrm{F}}\left(\mathrm{mg} \mathrm{g}^{-1}\left(\mathrm{~L} \mathrm{mg}^{-1}\right) 1 \mathrm{n}^{-1}\right)$ & 54.2 & 121.3 \\
\hline & $\mathrm{n}$ & 3.85 & 4.55 \\
\hline & $\mathrm{R}^{2}$ & 0.874 & 0.828 \\
\hline Gibb's free energy & $\Delta \mathrm{G}^{\mathrm{o}}\left(\mathrm{kJ} \mathrm{mol}^{-1}\right)$ & -5.78 & -11.1 \\
\hline
\end{tabular}

493

494

495

496

497

498 
499 Table 4. Comparison of maximum adsorption capacity of MB of CCF and DCCF to 500 other adsorbent materials (at $298 \mathrm{~K}$ ).

\begin{tabular}{|c|c|c|}
\hline \multirow{3}{*}{ Adsorbent precursor } & \multicolumn{2}{|l|}{ Maximum } \\
\hline & & Reference \\
\hline & \multicolumn{2}{|l|}{ capacity $\left(\mathrm{mg} \mathrm{g}^{-1}\right)$} \\
\hline Carbonized cigarette filter (CCF) & 212.8 & This work \\
\hline $\mathrm{P}$ and $\mathrm{N}$ co-doped cigarette filter (DCCF) & 303.0 & This work \\
\hline Banana peel & 227.2 & {$[28]$} \\
\hline Coffee grounds & 181.8 & {$[29]$} \\
\hline Coconut leaves & 66.0 & {$[30]$} \\
\hline Sludge & 46.7 & {$[31]$} \\
\hline Rice husk & 33.9 & {$[32]$} \\
\hline Seed pod & 14.8 & {$[33]$} \\
\hline
\end{tabular}

501 


\section{Supporting Information}

\section{Phosphorus and nitrogen co-doped carbon derived from Cigarette Filter for adsorption of methylene blue dye from aqueous solution}

Samantha Macchi ${ }^{1}$, Zane Alsebai ${ }^{2}$, Fumiya Watanabe ${ }^{3}$, Arooba Ilyas ${ }^{1}$, Shiraz Atif ${ }^{1}$, Tito Viswanathan ${ }^{1}$ and Noureen Siraj ${ }^{1, *}$

1 Department of Chemistry, University of Arkansas at Little Rock, 2801 S. University Ave, Little Rock, AR 72204, USA; spmacchi@ualr.edu, ZA, AI, SA, txviswanatha@ualr.edu, nxsiraj@ualr.edu

2 Little Rock Central High School, 1500 Park Street, Little Rock, AR 72202, USA; zane.abdeen.alsebai@gmail.com

3 Center for Integrative Nanotechnology Sciences, University of Arkansas at Little Rock, 2801 S. University Ave, Little Rock, AR 72204, USA; fxwatanabe@ualr.edu

* Correspondence: nxsiraj@ualr.edu; (501-916-6544)

\section{FTIR}

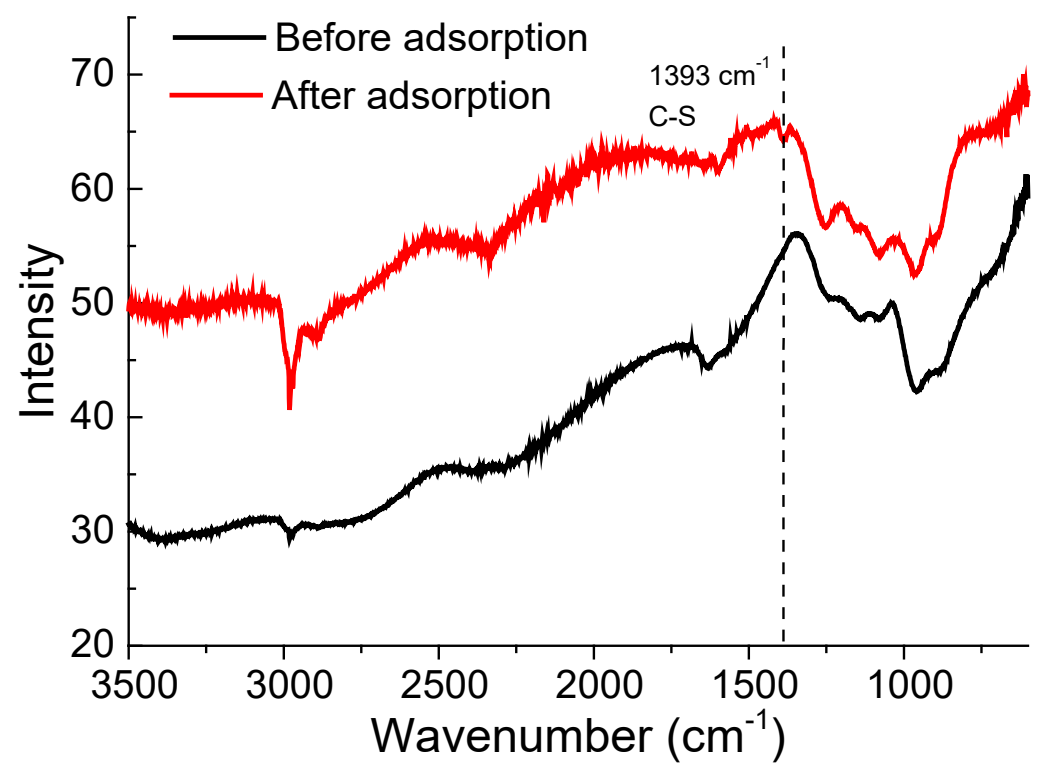

Figure S1. FTIR of CCF before and after adsorption

Adsorption modelling 

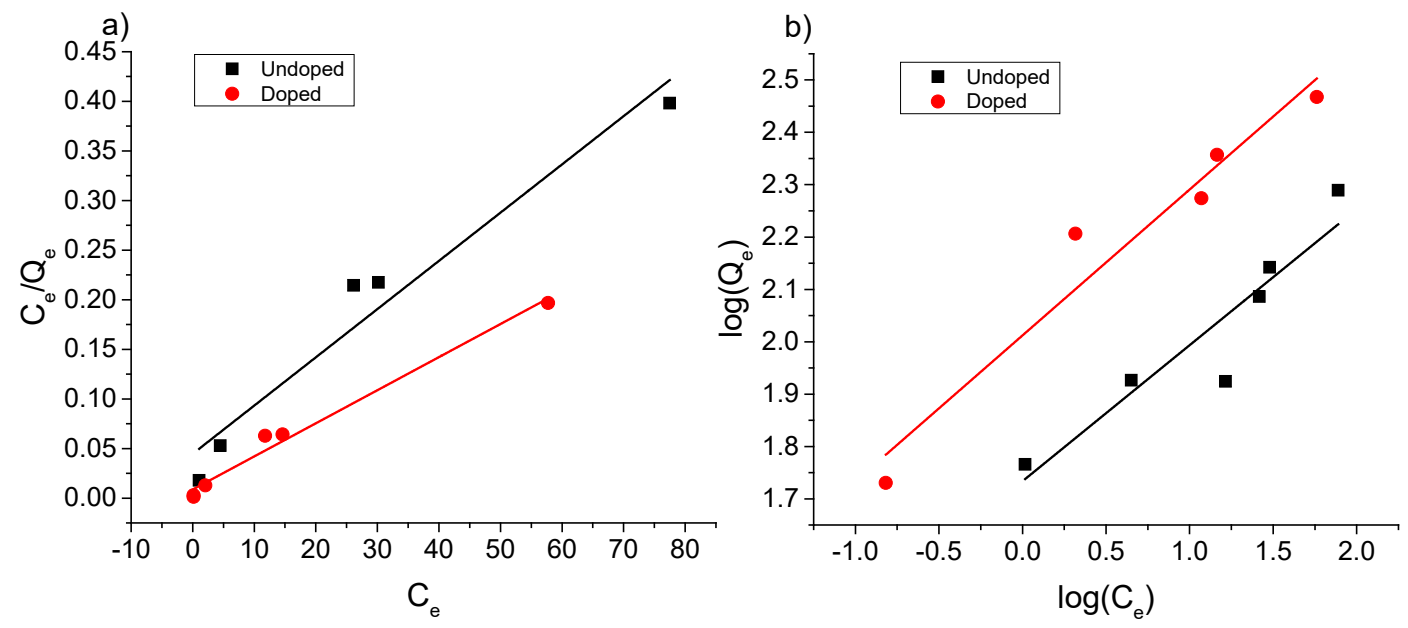

Figure S2. a) Langmuir fitting and b) Freundlich fitting of CCF and DCCF adsorption data from Figure 7.

\section{Kinetic modelling of undoped sample data}

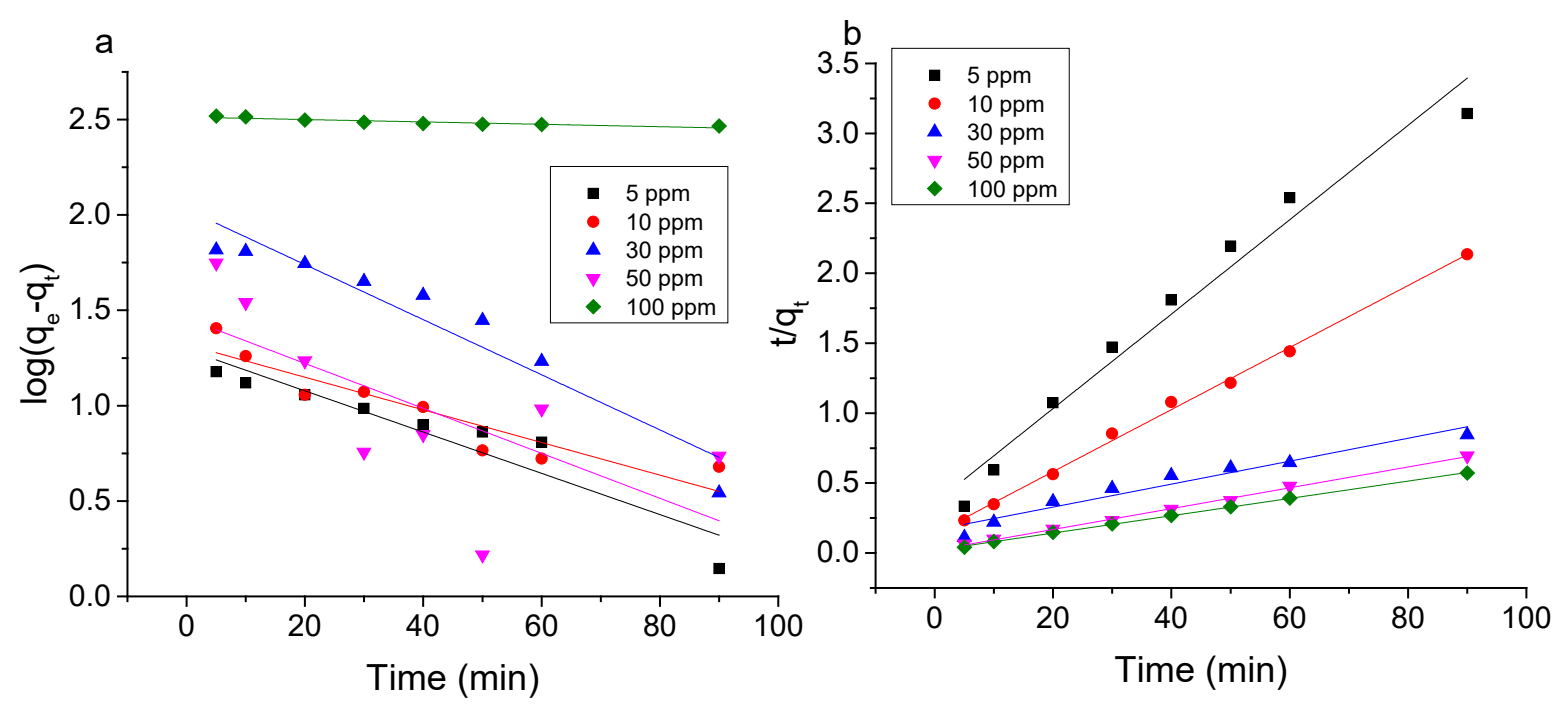

Figure S3. A) Pseudo first and b) pseudo second order fitting for CCF kinetic data from Figure 8a. 
Table S1. Results of fitting of pseudo first and second order kinetic models on adsorption onto CCF and PNCF.

\begin{tabular}{|c|c|c|c|c|c|c|c|c|c|}
\hline \multicolumn{10}{|c|}{$\mathrm{CCF}$} \\
\hline \multicolumn{5}{|c|}{ Pseudo-first order } & \multicolumn{5}{|c|}{ Pseudo-second order } \\
\hline $\begin{array}{c}\mathrm{C}_{0} \\
(\mathrm{ppm})\end{array}$ & $\begin{array}{l}\mathrm{Q}_{\mathrm{e}, \mathrm{cal}} \\
(\mathrm{mg} / \mathrm{g})\end{array}$ & $\begin{array}{c}\mathrm{k}_{1} \\
(1 / \mathrm{min})\end{array}$ & $\mathrm{R}^{2}$ & $\Delta q$ & $\begin{array}{c}\mathrm{C}_{0} \\
(\mathrm{ppm})\end{array}$ & $\begin{array}{c}\mathrm{Q}_{\mathrm{e}, \mathrm{cal}} \\
(\mathrm{mg} / \mathrm{g})\end{array}$ & $\begin{array}{c}\mathrm{k}_{2}(\mathrm{~g} / \mathrm{mg} \cdot \\
\min )\end{array}$ & $\mathrm{R}^{2}$ & $\Delta q$ \\
\hline 5 & 26.15 & 0.00290 & 0.988 & 6.98 & 5 & 23.78 & 0.00661 & 0.995 & 8.05 \\
\hline 10 & 44.67 & 0.00503 & 0.934 & 15.14 & 10 & 42.29 & 0.00326 & 0.993 & 1.03 \\
\hline 30 & 99.71 & 0.00438 & 0.940 & 19.90 & 30 & 90.47 & 0.00097 & 0.978 & 8.48 \\
\hline 50 & 134.24 & 0.00855 & 0.619 & 14.57 & 50 & 132.48 & 0.00193 & 0.995 & 5.90 \\
\hline 100 & 176.42 & 0.00039 & 0.911 & 8.80 & 100 & 154.29 & 0.00030 & 0.999 & 6.78 \\
\hline \multicolumn{10}{|c|}{$\mathrm{DCCF}$} \\
\hline \multicolumn{5}{|c|}{ Pseudo-first order } & \multicolumn{5}{|c|}{ Pseudo-second order } \\
\hline $\begin{array}{c}\mathrm{C}_{0} \\
(\mathrm{ppm})\end{array}$ & $\begin{array}{c}\mathrm{Q}_{\mathrm{e}, \mathrm{cal}} \\
(\mathrm{mg} / \mathrm{g})\end{array}$ & $\begin{array}{c}\mathrm{k}_{1} \\
(1 / \mathrm{min})\end{array}$ & $\mathrm{R}^{2}$ & $\Delta q$ & $\begin{array}{c}\mathrm{C}_{0} \\
(\mathrm{ppm})\end{array}$ & $\begin{array}{c}\mathrm{Q}_{\mathrm{e}, \mathrm{cal}} \\
(\mathrm{mg} / \mathrm{g})\end{array}$ & $\begin{array}{c}\mathrm{k}_{2}(\mathrm{~g} / \mathrm{mg} \cdot \\
\min )\end{array}$ & $\mathrm{R}^{2}$ & $\Delta q$ \\
\hline 5 & 28.47 & 0.00986 & 0.877 & 8.88 & 5 & 28.47 & 0.01479 & 0.999 & 6.79 \\
\hline 10 & 51.92 & 0.00812 & 0.953 & 4.52 & 10 & 50.63 & 0.00740 & 0.998 & 4.89 \\
\hline 30 & 100.84 & 0.00708 & 0.873 & 13.82 & 30 & 100.38 & 0.00578 & 1.000 & 5.36 \\
\hline 50 & 222.93 & 0.00968 & 0.987 & 16.97 & 50 & 223.71 & 0.00039 & 0.989 & 7.93 \\
\hline 100 & 300.40 & 0.00434 & 0.828 & 9.51 & 100 & 263.54 & 0.00117 & 0.995 & 8.44 \\
\hline
\end{tabular}

